\title{
AC 2008-2106: IMPROVING CAMPUS CLIMATE FOR FACULTY FROM UNDERREPRESENTED GROUPS
}

\section{Lisa McClain, Boise State University}

Lisa McClain is the Director of the Gender Studies Program at Boise State University and Associate Professor of History. Her research is interdisciplinary, involving women's studies, social sciences and history. Lisa has taken a leadership role in Boise State University's efforts to improve gender equity not only at the university by throughout Idaho.

\section{Cheryl Schrader, Boise State University}

Cheryl B. Schrader is Dean of the College of Engineering and Professor of Electrical and Computer Engineering at Boise State University. Dean Schrader has an extensive record of publications and sponsored reseearch in the systems, control and engineering education fields. She received the 2005 Presidential Award for Excellence in Science, Engineering and Mathematics Mentoring from the White House for an enduring, strong and personal commitment to underrepresented engineering students and faculty.

\section{Janet Callahan, Boise State University}

Janet Callahan is the Associate Dean for Academic Affairs at Boise State University and a Professor in the Materials Science and Engieering Department. Janet received her Ph.D. in Materials Science, her M.S. in Metallurgy and her B.S. in Chemical Engineering from the University of Connecticut. Her educational research interests include freshman engineering programs, math success, and recruitment and retention issues in engineering. 


\title{
Improving Campus Climate for Faculty from Underrepresented Groups
}

\begin{abstract}
A continuing challenge in engineering in higher education is that of professional equity regarding opportunity for advancement and job satisfaction due to differences in gender, race, ethnicity, sexual orientation, ability and other factors. Because there are more women and persons of color visible within engineering faculties and administrations than ever before, casual observers might conclude that significant progress has been made in creating an equitable climate in academia. A preponderance of recent studies, however, demonstrate that while women and individuals from other underrepresented groups have gained access to some faculty and administrative positions, this has not necessarily translated into consistent patterns of success through all levels of academic hierarchies and leadership positions. For example, some universities do a good job of recruiting and hiring women faculty and faculty of color, yet beyond this, both groups are consistently underrepresented at certain levels of faculty administration, such as department chair, dean, and endowed chairs. ${ }^{1-7}$

In 2005, Boise State University, a mid-sized, metropolitan university, administered a Campus Climate Survey to gain an understanding of how these national trends presented themselves on a particular campus, with the long-term goal of transforming campus climate and culture to enhance opportunities for underrepresented groups. In general, between two-thirds and threequarters of the faculty who responded to the survey reported that they have been treated fairly and equitably while at the university. The following analysis sheds light on the approximately one-quarter to one-third of faculty members who did not feel that they had been equitably treated while also focusing on responses from the science and engineering faculty in particular. Additionally, this paper explores ways in which engineering and science departments and universities can use climate data to inform strategic plans of action.
\end{abstract}

\section{Campus Climate Survey}

Equity in academia involves a variety of factors: in addition to hiring and promotion rates, equity includes more subtle issues such as access to leadership opportunities and key committee assignments, allocation of resources, the public valuation of research agendas, recognition and awards, policies and procedures that take into account the needs of the majority as well as underrepresented groups, and, perhaps most importantly, university, college and departmental culture that promotes perceptions of fair and equal treatment. ${ }^{8}$ The current institutional culture at most colleges and universities values a traditional type of leadership that often does not recognize the distinctive talents and achievements of women, ethnic and racial minorities, those with disabilities and those of a variety of sexual orientations. Faculty drawn from these underrepresented groups are often advised how to "work the system" already in place. ${ }^{9}$ Such faculty struggle to reconcile their gender identities, family priorities, cultural norms, and personal values with a conflicting university culture and institutional imperatives that make little real accommodation for diverse needs. In many cases, job dissatisfaction results, leading to low retention rates for faculty from underrepresented groups. ${ }^{10-13}$ Ironically, these are often the faculty members that universities are working hardest to recruit and retain. 
In Fall 2005, Boise State University administered a Campus Climate Survey to faculty, staff and students. The results from the faculty portion of the survey are allowing the university to begin the process of cultural transformation. Science and engineering ( $\& \& E$ ) faculty at the university are taking a key leadership role in addressing these issues for S\&E faculty from underrepresented groups, with the long term goal of incorporating the gains they have made into the university as a whole for faculty, staff, and students. They have forged a coalition of key faculty and staff across campus who exercise responsibility for, and interest in, equity issues. This coalition has applied for an NSF ADVANCE Grant for Institutional Transformation. These S\&E leaders are also the first subgroup to request a microanalysis of Campus Climate Survey results specific to their disciplines and interests.

In Spring 2005, the university provost charged a 21-member committee comprised of faculty, administrators, staff, students, and a community member to develop and administer the survey and analyze the responses. The committee undertook an extensive review of model campus climate surveys from across the nation, including those from the University of WisconsinMadison, the University of Arizona, the University of Washington, and the California system, prior to developing faculty, staff and student survey instruments best suited to their campus. Survey instruments were peer reviewed as well as analyzed by experts in Institutional Analysis Assessment \& Reporting. "The principle objectives of the survey were to identify and gauge perceptions of the campus community about equity in regard to issues of age, gender, faith, ability, nationality, race/ethnicity, veteran status, political ideology and sexual orientation; identify what students, staff and faculty perceive as roots or cause of inequity on campus; and gather input regarding possible solutions or actions that the university should take that would change the respondents' perceptions regarding equity on campus." ${ }^{14}$ The online survey took place from November 17 to December 5, 2005. Campus personnel received an email from the university president and students received an email from the student association president announcing the survey and providing the appropriate link to faculty, staff or student versions of the survey. In addition, banners were posted in visible, high traffic areas around campus, and fliers were mailed to all faculty and staff to encourage participation. After the closing of the survey, a subgroup of the original Campus Climate Committee quantitatively and qualitatively analyzed the data. Analysts used SPSS to complete the quantitative data analysis. The qualitative data was analyzed using domain analysis, categorizing responses into broad themes and issues brought up by multiple respondents into the most comprehensive representation of the entire group of respondents. This subgroup merged their reports and prepared a 150-page report of the overall findings which was submitted to the provost after extensive peer review.

University-wide, between two-thirds and three-quarters of the overall faculty who responded to the survey ( $53 \%$ of faculty responded; $\mathrm{n} \sim 361$ ) reported that they have been treated fairly and equitably while at the university. Significantly, those faculty among the one-third to one-quarter who reported that they had not received equal treatment and opportunities for leadership and advancement tended to come from underrepresented groups such as women, racial/ethnic minorities, and individuals with disabilities that engineering departments and universities are trying to recruit and retain. And while over $90 \%$ of faculty members were aware of policies in place to protect them against discrimination, harassment and intimidation, faculty appear to question the extent to which such policies are enforced, both for themselves and for other faculty 
members, particularly from the specific subgroups mentioned above. Two-thirds of faculty overall (67\%) reported that they feel comfortable bringing up issues of discrimination and harassment in the workplace.

\section{Climate for Science and Engineering Faculty}

The rest of this analysis attempts to shed light on S\&E faculty more specifically, in contrast with the wider university faculty population, and on the experiences of certain underrepresented groups among the S\&E faculty: women, persons of color, and those who identified as Lesbian/Gay/Bisexual/or Transgender/Transsexual (LGBT). Other categories - such as age, level of ability, faith, political ideology, country of origin, and veteran status - were also analyzed but are not part of this discussion due to space limitations. For the three groups under discussion women, persons of color, and LGBT faculty - four survey categories with the most relevance for this analysis are:

- Fair and Equal Treatment for Self and Others at Boise State University,

- Valuation of a Faculty Member's Work by the University,

- Equal Opportunities for Leadership and Advancement, and

- Experiences of Harassment and Intimidation.

At this university, tenured and tenure track S\&E faculty are spread over 20 departments and total 195 individuals. In broad terms this includes faculty from the College of Engineering, mathematics, and biological, physical, social and behavioral sciences. The Campus Climate Survey asked faculty participants to identify with a college, such as the College of Engineering, or with a specific division, such as the Sciences (mathematics, chemistry, physics, and biology) within the College of Arts and Sciences. Faculty from the nine behavioral or social science departments outside of Engineering or Arts and Sciences were not distinguishable in this survey and were included in the university faculty at large. Thus, the term S\&E from this point forward in this paper refers to faculty from all seven departments in the College of Engineering and the four science departments in the College of Arts and Sciences, with the largest percentage of respondents from Engineering.

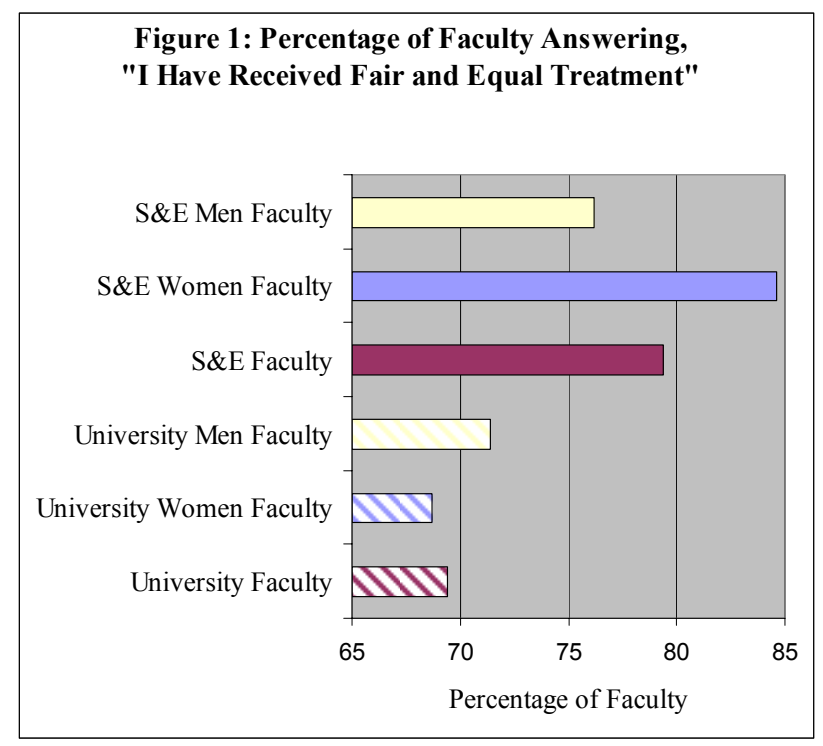

Overall, $43 \%$ of S\&E tenured and tenure track faculty responded to the Campus Climate Survey. S\&E women faculty are much more likely than faculty women generally at the university to agree or strongly agree that they have been treated fairly and equally while at the university, that their work is valued, and that they have enjoyed equal opportunities for leadership. In fact, S\&E women faculty report higher levels of agreement on these issues than men S\&E faculty. The possible reasons for this will be analyzed below. And although their numbers were too small to analyze quantitatively, S\&E faculty of color and LGBT S\&E faculty provided some key 
insights into efforts to transform campus climate and culture. Both groups identified where campus leadership to effect change might come from and whether any areas within the academic hierarchy exist where improvements might be made. But first we will take a look at each category - gender, race/ethnicity, and sexual orientation - more closely.

Gender: When compared to the general university faculty population, a higher proportion of S\&E faculty (79.4\%) reported that they had been treated fairly and equally while employed at the university, as compared to $69.4 \%$ for all university faculty; see Figure 1. Eighty-four percent of women S\&E faculty, however, reported levels of fair and equitable treatment as compared to $76 \%$ of men S\&E faculty and at levels much higher than university women faculty more generally (69\%). Of the $16 \%$ of women S\&E faculty reporting unfair or unequal treatment, threequarters perceived that age, gender, and political ideology were at the root of their perceived unfair/unequal treatment; one-half reported family responsibilities as contributing to their perceived unfair or unequal treatment; and one-quarter reported race/ethnicity as a causal factor, reminding us that there is often overlap among underrepresented groups.

When asked if other faculty at the university had received fair and equal treatment there, women and men S\&E faculty as well as men faculty in the university as a whole were much more likely (69\% for each group) and at similar rates to report that their colleagues were treated fairly and equitably campus wide than were women faculty at the university as a whole (59\%); see Figure 2.

When asked whether they thought the university valued their work, $76 \%$ of the Boise
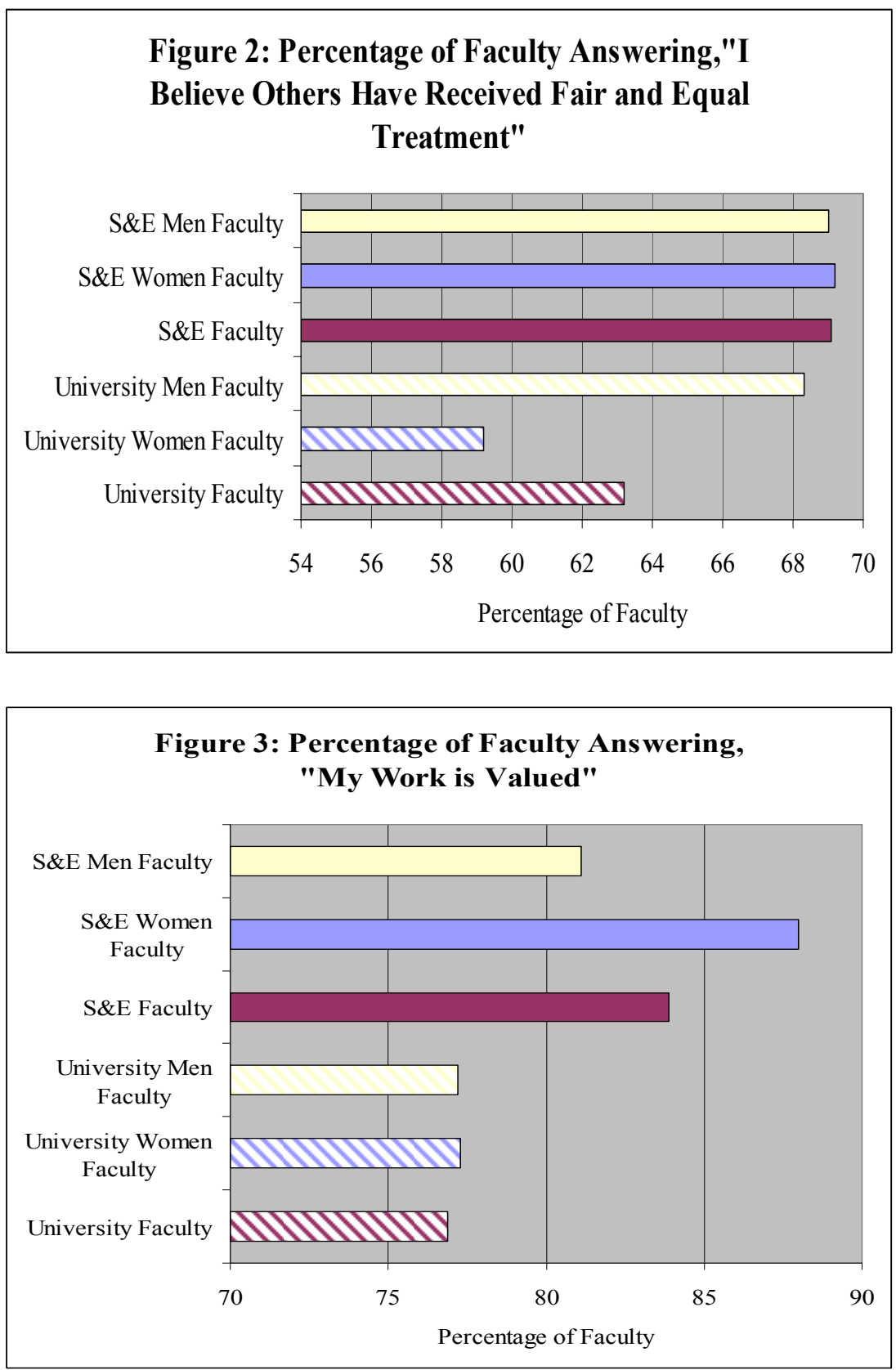
State University faculty respondents believe their work at the university is valued; however a higher percentage - approximately $84 \%$ - of S\&E faculty believe their work is valued; see Figure 3 . When this is broken down by gender, male S\&E faculty are somewhat more satisfied that their work is valued by the university $(81 \%$ vs. $77 \%)$ than male faculty university-wide, but women $\mathrm{S} \& \mathrm{E}$ faculty are satisfied at a rate almost 11 percentage points higher than the general female faculty population ( $88 \%$ vs. $77 \%)$ that their work is valued. Moreover, as with the issue of fair and equal treatment, more women S\&E faculty are satisfied $(88 \%)$ that their work is valued than men $\mathrm{S} \& \mathrm{E}$ faculty $(81 \%)$.

When asked if they had received equal opportunities for leadership and advancement regardless of gender $76 \%$ of S\&E women faculty agreed or strongly agreed that they had, as compared with $61 \%$ of women faculty university-wide. Additional response details for this question are presented in Figures 4 and 5.
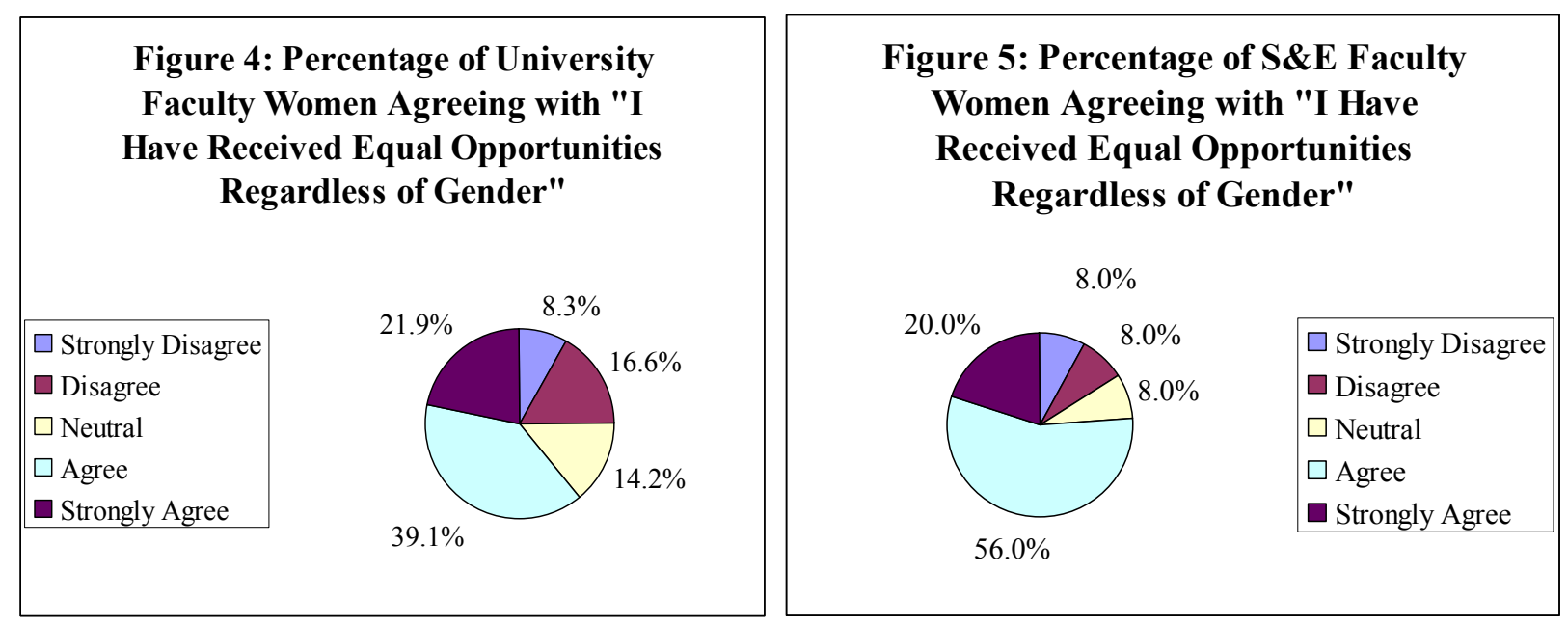

In terms of issues of harassment and discrimination, S\&E women faculty were just as aware that there were policies and procedures in place at the university to protect them from harassment and discrimination as their female colleagues university-wide. S\&E women faculty, however, were much more comfortable (76\% vs. 64\%) bringing up issues of discrimination and harassment on campus than were women faculty university-wide; and S\&E women faculty were more likely to go to their dean or to human resources first than to their department chair or upper administration with these issues. This latter point will be discussed in more detail later. Approximately equal percentages of women S\&E faculty and women faculty throughout the university $(69 \%$ and $67 \%$ ) reported that their experiences at the university had been free of harassment and intimidation. Among the approximately one-third of women faculty who reported that their experiences had not been free of harassment, 75\% of S\&E women faculty reported that they had been harassed or intimidated because of their gender as compared with $82 \%$ of women faculty university-wide. Approximately one-half of all women faculty who claimed to have been harassed or intimidated at the university reported the incident, but women S\&E faculty who did report the incident were more likely to perceive that their complaint had been handled with sensitivity and fairness than were women faculty university-wide. 
Race/Ethnicity: Only $10.9 \%$ of S\&E faculty respondents identified as persons of color, whereas $12.6 \%$ of university faculty respondents did. With the number of faculty of color in S\&E disciplines small, quantitative analysis is problematic; still, some patterns revealed by the respondents should be explored. Approximately 29\% of S\&E faculty of color reported that they had not received fair and equal treatment while at Boise State University, but only one attributed the unfair or unequal treatment to race/ethnicity. All who chose to answer the question reported their work is valued at Boise State University. Approximately $29 \%$ of S\&E faculty of color also reported that their experiences here had not been free of harassment and intimidation.

Significantly, only $57.2 \%$ of S\&E faculty of color reported that they knew there were policies in place to protect them from such harassment and discrimination as compared with $90 \%$ of the $S \& E$ faculty as a whole. Almost one-third of faculty of color were not comfortable bringing up issues of harassment and discrimination. The one faculty member who reported an incident of harassment and/or discrimination reported that the complaint was not handled fairly or with sensitivity.

Sexual Orientation: Although the number of S\&E faculty members identifying as Lesbian/Gay/Bisexual/or Transgender/Transsexual (LGBT) was too small for statistical analysis, the responses to key questions, such as experiences of harassment should be explored. For example, these faculty members all agreed that they had received fair and equal treatment at the university and were not uncomfortable bringing up equity issues. They disagreed or strongly disagreed, however, that they were aware that there were policies in place at the university to protect them from intimidation or harassment. LGBT faculty members reported that their experiences at Boise State University had not been free of harassment and intimidation but only one attributed the harassment and intimidation to sexual orientation. One faculty member reported an incident and was satisfied that the university handled the complaint with fairness and sensitivity. The faculty members also disagreed or strongly disagreed that Boise State University enforces policies concerning unequal treatment based on sexual orientation. One LGBT faculty member in S\&E did not feel that their work was valued by the university but that faculty member did not attribute the devaluation of their work to their sexual orientation.

\section{Where Should Change Occur?}

So how does a midsize, metropolitan university build upon its successes and begin to address these perceptions about fair and equal treatment, valuation of work, opportunity for leadership and advancement, and harassment and intimidation on campus in a comprehensive, meaningful way to create measurable systemic change? During the past five years, the College of Engineering at Boise State University has made a determined effort to recruit and retain women faculty and administrators. Recently the college was ranked second in the nation in terms of percentage of women faculty and second in the nation in terms of the number of women in leadership positions. ${ }^{15,16}$ Forty percent of leadership positions - dean, associate dean, department chairs and research center directors - currently are held by women, which may indicate that the broadening of ideas of what constitutes leadership to include gendered perspectives and contributions is already occurring in this college. In such an environment it is gratifying to note that $\mathrm{S} \& \mathrm{E}$ women faculty responded quite positively to questions of climate. Increased confidence at the dean and department level and the fact that these faculty are more comfortable discussing issues of harassment or intimidation leads to the conclusion that this 
environment is already fairly open and supportive to one underrepresented group of faculty. This is supported by the increased satisfaction of S\&E men faculty as compared to university faculty overall or to their university male counterparts. These accomplishments are laudable but only the beginnings of a coordinated, comprehensive approach to address equity issues for a variety of underrepresented groups in the long term.

Moreover, the fact that the overall university faculty - including faculty from the social and behavioral sciences - lag behind in feeling their work is valued or in believing they have been provided equal opportunity for advancement brings to the fore the importance of departmental and college climate. Much work remains to be done in terms of gender, and with respect to ethnicity and sexual orientation in all areas. Although certain previous studies have found that equity problems "reside primarily in individual departments rather than at the university level," we propose that a consistent university-wide approach is needed to correct these inequities, rather than one limited to S\&E departments or colleges alone. ${ }^{3}$ The challenges of lack of accountability and a diffusion of responsibility throughout the university inhibit the creation of an equitable climate and culture in ways that cannot be eliminated by isolated departmental approaches. Yet, administrators and faculty at all levels must be engaged in on-going dialogue about equity issues if entrenched campus culture is to change.

Boise State University would be well served to examine best practices among S\&E units (colleges and departments) in terms of inclusiveness and to formalize and replicate them campus-wide. As universities such as the University of Arizona and the University of Pennsylvania have observed, tackling equity issues is a university-wide effort that must involve administration, faculty, staff and students. ${ }^{3,11}$ Furthermore, someone very visible in the institution must take responsibility for communicating the importance of equity issues to institutional culture and enforcing them if policies are to have any effect on campus climate. Such leadership from top levels of authority is key. Diffusion of responsibility throughout the university historically has not produced the creation of an equitable university climate and culture. ${ }^{3}$ Policies and procedures are critically important but they are only a beginning step, not a sufficient means to assure an equitable campus climate. There must be on-going dialogue about equity issues, led by a visible individual in authority if entrenched campus climate and culture are to change.

The purpose of the next set of results is to identify where such leadership might come from at Boise State University and whether any areas within the academic hierarchy exist where improvements might be made. Such results are not intended to place blame or point fingers but rather to suggest opportunities to improve campus climate. Faculty university-wide expressed the most confidence in upper administration at the provost, vice president and president level. Faculty revealed a relatively high confidence in departmental culture as well. The faculty expressed the lowest confidence $(28 \%)$ that there was a commitment to inclusiveness at the college/division level. Since this is the hierarchical link between faculty residing within departments and the top levels of administration - in whom most faculty place the majority of confidence - effective education, dialogue and involvement of college-level administrators in tackling campus climate equity issues appears to be an important step in addressing equity. Since many faculty from underrepresented groups university-wide indicated they had not enjoyed 
equal opportunities for leadership and career advancement, and since the college level is one of the first avenues for leadership, significant action should be focused on this area.

Moreover, targeted analysis of the S\&E faculty responses to these issues reveals that leadership to achieve equity is more complex than department/college/upper administration hierarchies. Faculty members from different underrepresented groups expressed confidence in different levels of administration to provide leadership toward an equitable climate. For example, women across the university and S\&E women faculty expressed a much greater degree of confidence in their college leaderships' commitment to inclusivity (53\% and 62\%) than did the faculty throughout the rest of the university; see Figures 6 and 7. Confidence in departmental and university leadership from S\&E women faculty approximated that of the university faculty as a whole.
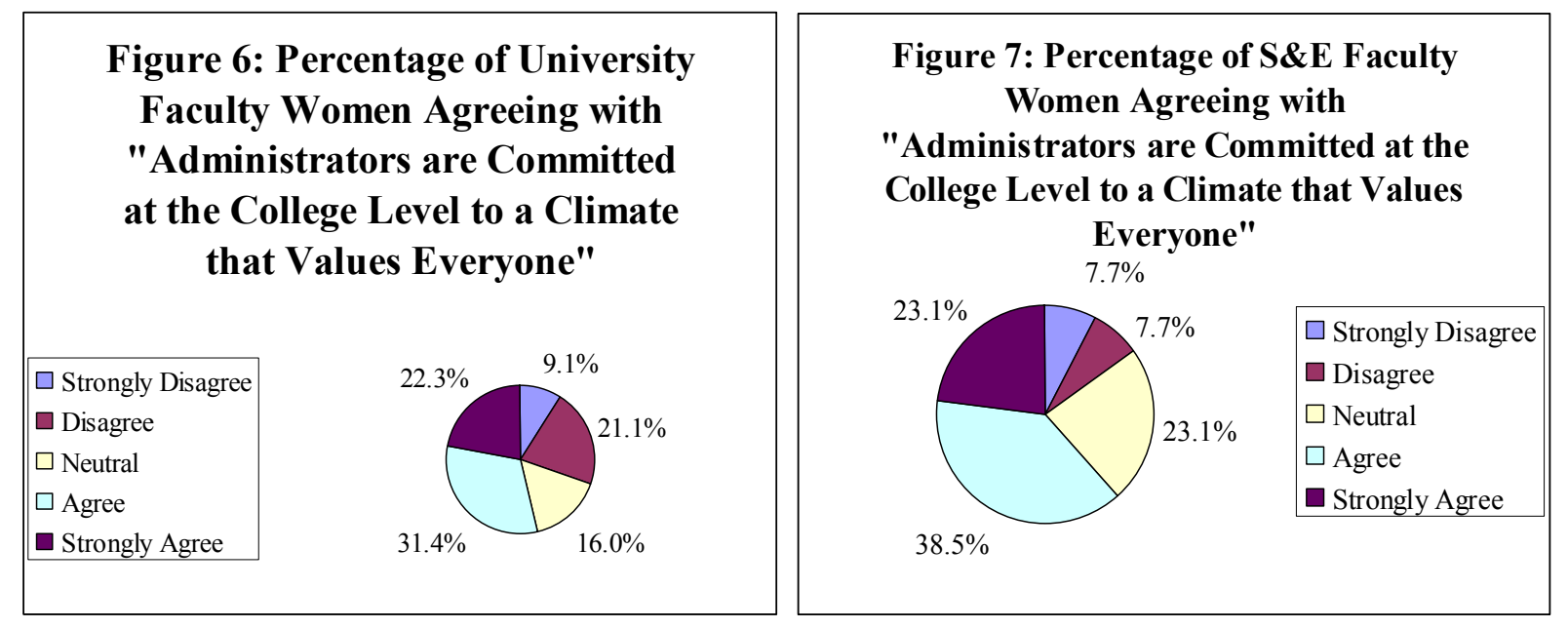

LGBT faculty members, on the other hand, reported confidence that administrators at the departmental level were committed to a climate which values everyone, but were less certain that this was true of administrators at the college level. LGBT faculty members definitely disagreed that upper-level administrators - those at the provost, vice president and president level - were committed to an inclusive environment for everyone.

S\&E faculty members of color painted an even different picture. They reported least confidence (57.1\% agreed/strongly agreed) that administrators at the departmental level were committed to a climate that values everyone, but were slightly more certain that this was true of administrators at the college level and most confident $(83.3 \%)$ that this was true at the level of upper administration.

These varying patterns among S\&E faculty from underrepresented groups indicate that S\&E departments are perceived as responsive to certain equity issues but perhaps do not yet possess a universal awareness and approach to promote equity for all underrepresented groups, an ambitious but not unachievable goal to be sure. It suggests the dangers of a one-size-fits-all approach to creating an equitable climate. It indicates the importance of education on a variety of intersecting equity issues, a multi-pronged approach to the creation of an inclusive and equitable 
climate in S\&E disciplines as well as at the university level. Primarily, universities should avoid the easy assumption that all equity issues should be handled in the same way and will be received with the same degree of satisfaction by differing groups.

\section{Discussion}

Although most universities have policies in place designed to promote equity, unfortunately women and other minority faculty often become professionally stalled by subtle forms of disadvantage interwoven into university culture which policy alone fails to eliminate. ${ }^{3,17}$ This is true for faculty university-wide as well as for S\&E faculty as indicated by survey responses. The devaluation of a faculty member's "non-traditional" research agenda, the inflexible weighting of teaching/research/service workloads related to promotion and tenure, toleration of sexist or racist comments, de facto exclusion from informal social events, or lack of flexibility regarding family care issues are all covert barriers to an equitable environment for both access and success in the academy. It is at the level of university culture - the deeply embedded organizational values that resist change - and climate - the current atmosphere and attitudes at an institution that are more malleable - that efforts for institutional transformation must be directed in the long term. ${ }^{18,19}$

The National Initiative on Women in Higher Education, for example, believes that in order to guarantee full participation in the academy, and particularly in academic leadership, we must redefine leadership itself rather than expect all individuals to conform to a one-size-fits-all model of accomplishment. ${ }^{17}$ By broadening our ideas of what constitutes achievement and leadership to include the ways in which specific gender or culturally related behaviors can enhance institutional success through innovative research agendas, leadership opportunities, and enhanced job satisfaction, we can bring innovative and progressive people and ideas into our university that will enhance Boise State's competitiveness, achievement, and excellence.

Although the climate survey results revealing a high rate of satisfaction around equity issues among women S\&E faculty at this midsize, metropolitan university might seem somewhat surprising in light of larger national trends, they should also be acknowledged as representative of a large segment of academic institutions that frequently don't get much press when issues of equity are discussed. Many types of institutions are tackling equity issues, not just large, established research universities whose climates are most often studied and presented as normative for the nation. Metropolitan universities cater to a different clientele and may be able to attract and retain a more diverse faculty and student body. It is in such an environment that real progress toward professional equity can be made, since these universities may hire women and faculty from other underrepresented groups more frequently and success may not be quite as narrowly defined as at the larger research universities. It can be argued that metropolitan universities, particularly those that are in the expansion phase, have the greatest opportunity to change climate and shape culture in the shortest amount of time. It is these institutions where creative solutions can be implemented, often out of necessity, and a large degree of influence observed.

Equally as important in S\&E is the value placed on technology in the community surrounding a given university, which can prevent feelings of isolation and marginalization by faculty typically underrepresented in academe. Boise State University is located at the center of one of the 
nation's notable high technology areas. Engineers and scientists form a large percentage of the workforce, and contribute substantially to the strong economy in the state. The sense of purpose and satisfaction experienced by S\&E faculty should be commonplace across the institution, not just in the College of Engineering and part of the College of Arts and Sciences, where it sees that accomplishments are recognized by the community as well as the university. It would be interesting to know how faculty in the Arts division of the College of Arts and Sciences responded to the survey as compared to the Sciences division. A study into faculty climate in the softer sciences would also provide additional and important insight.

Using the results of the survey, S\&E leadership at Boise State University will formally engage and educate faculty members, chairs, and deans on critical climate issues, existing policies, and policy reforms in progress. A one-size-fits-all approach will be avoided. Particular emphasis will be placed on educating about a variety of equity issues impacting different populations.

\section{Conclusions}

Boise State University is well positioned to increase equity of women and other underrepresented groups. Regional economic expansion, demographic shifts, development of a significant high tech infrastructure and dynamic university leadership have all converged to create a unique opportunity to transform the culture of this institution to reach its strategic vision of becoming a metropolitan research university of distinction. However, care must be taken to truly understand which groups have embraced change and diversity, which require and deserve additional opportunities, and what best practices can be adopted on a broader level.

To realize true cultural transformation, university leadership must be willing to critically access the university as a whole - such as Boise State University began to do through its Campus Climate analysis - and their individual units to determine how to improve climate and to be accountable for it. Advances with each underrepresented group may require different strategies, but will improve the satisfaction of the whole and lead to a pivotal shift in culture. Working with faculty from underrepresented groups is a good start to shaping the dynamic, innovative team that will work together to resolve the important and critical issues challenging us today.

\section{Bibliography}

1 Massachusetts Institute of Technology. (1999). A Study on the Status of Women Faculty in Science at MIT: How a Committee on Women Faculty Came to be Established by the Dean of the School of Science, What the Committee and the Dean Learned and Accomplished, and Recommendations for the Future. Cambridge, MA.

2 Nelson, Donna J. (2005, January) A National Analysis of Diversity in Science and Engineering Faculties at Research Universities. Norman, OK. http://cheminfo.chem.ou.edu/ djn/diversity/briefings/Diversity $\% 20$ Report $\% 20$ Final.pdf

3 University of Pennsylvania Gender Equity Report. (2001). http://www.upenn.edu/almanac/v48pdf/011204/GenderEquity.pdf

4 Valian, Virginia. (1998). Why So Slow? The Advancement of Women. Cambridge, Mass.: MIT Press. 
5 Moses, Yolanda. (2003, September). "Shifting the Affirmative Action Focus from Access to Success." Anthropology News, p. 9.

6 Hollenshead, Carol S., Stacy A. Wenzel, Barbara B. Lazarus, and Indira Nair. (1996). "The Graduate Experiences in the Sciences and Engineering: Rethinking a Gendered Institution." In The Equity Equation; Fostering the Advancement of Women in the Sciences, Mathematics and Engineering. San Francisco: JosseyBass Publishers. pp. 122-162.

7 Utah State University. (2002). NSF ADVANCE - Utah State Proposal, Improving the Recruitment and Retention of Women Faculty in the Sciences and Engineering: Applying a Business Model to a University. http://websites.usu.edu/advance/Document/index.asp?Parent=6293

8 Thom, Mary. (2001). Balancing the Equation: Where are Women and Girls in Science, Engineering and Technology? New York: National Council for Research on Women. Chapter 3.

9 Sandler, Bernice R. (1992). Success and Survival Strategies for Women Faculty Members, Association of American Colleges and Universities, Washington, DC.

10 Astin, H.S., Antonio, A.L., Cress, C.M., and Astin, A.W. (1997). Race and Ethnicity in the American Professoriate, 1995-96. Los Angeles: Higher Education Research Institute.

11 Cress, C. (2001). The Millennium Project: Report in Detail. Tucson, AZ: University of Arizona, Office of the President.

12 Toren, T. (2000). "The subtle ways of differential treatment." Hurdles in the Halls of Science. pp. 73-76, Lahnam, MD: Lexington Books.

13 Tierney, W. G. (1993). Building communities of difference: Higher Education in the Twenty-First Century. Westport, Conn: Bergin and Garvey.

14 Boise State University. (2006) Campus Climate Executive Summary \& Recommendations. p. 1. http://www.boisestate.edu/provost/documents/pdf/executive-summary.pdf

15 American Association for Engineering Education Connections Newsletter. (2007, October). Databytes. November 6, 2007. http://www.asee.org/publications/connections/

16 Women in Engineering Programs and Advocates Network (WEPAN). (2006, May). "Women in the Field of Engineering: Dean, Department Chair, Provost, President." CO: Denver. May 11, 2006.

17 Barceló, Rusty and Patricia M. Lowrie. (2003). "Transforming Leadership: Women of Color use Cultural Identity as a Tool." National Initiative, Volume 32, Issue 3-4. Association of American Colleges and Universities on Campus with Women. See also Barceló, Rusty. (2004). "The Courage to Lead." OCWW, National Initiative, Volume 32, Issue 2. Association of American Colleges and Universities.

18 Kuh, G.D., \& Whitt, E.J. (1988). "The Invisible Tapestry: Cultures of American Colleges and Universities." ASHE-ERIC Higher Education Report, No. 1. Washington, DC: Association for the Study of Higher Education.

19 Peterson, M. \& Spencer, M. (1990). “Understanding Academic Culture and Climate." In W. Tierney (Ed.), Assessing Academic Climates and Cultures. San Francisco, California: Jossey-Bass, Inc. 